\title{
A Imagem do Rio de Janeiro Projetada por Turistas em uma Mídia Social: experiência, qualidade e valor*
}

\author{
Verônica Feder Mayer ${ }^{a}$ \\ Andressa Martins da Silvab \\ Liana Cid Bárciac
}

\section{Resumo}

O compartilhamento de informações em mídias sociais possibilita que as pessoas tenham acesso de maneira rápida e gratuita a um conteúdo gerado por turistas que já vivenciaram determinada experiência, o que pode influenciar a escolha de outros, e impõe uma nova dinâmica às relações de consumo, afetando a imagem e a competitividade dos destinos. Este estudo investigou a imagem projetada por turistas que visitaram o Rio de Janeiro nos anos de 2015 e 2016 em relação aos seguintes aspectos: experiência nos principais atrativos da cidade, qualidade percebida dos serviços e julgamento de preço e valor. Para tal, foi realizada a análise de conteúdo de 612 comentários postados no site TripAdvisor, a mídia social dedicada ao turismo de maior audiência no mundo. Os resultados mostram que a grande maioria dos turistas relatou experiências favoráveis, avaliou positivamente a qualidade dos serviços e o valor, apresentando altos níveis de satisfação nos principais atrativos da cidade. As dimensões da experiência mais presentes nos comentários foram a estética e o entretenimento, reforçando a importância das belezas naturais e arquitetônicas na formação da imagem do Rio de Janeiro. Quanto aos comentários com teor negativo, a análise do conteúdo revelou pontos que devem ser monitorados e aprimorados por gestores públicos e privados ligados ao turismo.

Palavras-chave: Turismo; Mídias sociais; Conteúdo gerado pelo usuário; Imagem de destinos turísticos; Comportamento do consumidor.

\section{Abstract \\ The Image of Rio de Janeiro Projected by Tourists in a Social Medium: experience, quality and value}

Sharing information in social media enables people to access quickly and freely content created by tourists who have already lived a certain experience, which can have influence on the others' choices and imposes a new dynamic to consumption relations, impacting the destinations' image and competitiveness. This study investigated the image projected

* Fomento do CNPq e da Faculdade de Turismo e Hotelaria da Universidade Federal Fluminense (UFF).

a. Doutora em Administração pelo Instituto Coppead da Universidade Federal do Rio de Janeiro (UFRJ) com extensão na University of Illinois at Urbana-Champaign. Professora Associada da Faculdade de Turismo e Hotelaria da Universidade Federal Fluminense (UFF), coordenadora do Curso de Bacharelado Turismo, membro do corpo docente do Mestrado Acadêmico em Turismo da UFF, e coordenadora do Laboratório de Estudos de Consumo e Comportamento (Labcons - grupo de pesquisa CNPQ). Niterói, Rio de Janeiro, Brasil. E-mail: veronicamayer@id.uff.br

b. Bolsista de iniciação científica, pesquisadora do Observatório do Turismo da UFF e do Labcons. Discente do curso de Turismo da Faculdade de Turismo e Hotelaria da UFF. Niterói, Rio de Janeiro, Brasil. E-mail: andressamartins265@gmail.com

c. Bolsista de iniciação científica, pesquisadora do Observatório do Turismo da UFF e do Labcons. Bacharel em Turismo pela Faculdade de Turismo e Hotelaria da UFF. Niterói, Rio de Janeiro, Brasil. E-mail: lianabarcia@id.uff.br 
by tourists who visited Rio de Janeiro in 2015 and 2016 concerning the following aspects: experience in the city's main attractions, perceived quality of services, and evaluation of prices and value. For such, it was performed a content analysis of 612 comments posted on the TripAdvisor website, the most consulted social medium oriented towards tourism in the world. The results showed that most of tourists reported favorable experiences, evaluated service quality and values positively, presenting high level of satisfaction in the city's main attractions. The experience dimensions most present in the comments were esthetic and entertainment, reaffirming the significance of natural and architectural wonders in the constitution of Rio de Janeiro's image. Regarding the negative comments, the content analysis showed points that must be monitored and improved by public and private administrators connected to tourism.

Keywords: Tourism; Social media; User-generated content; Tourist destinations image, Consumer behavior.

\section{Resumen}

\section{La Imagen de Río de Janeiro Proyectada por los Turistas en un Medio Social: experiencia, calidad y valor}

El intercambio de información en las redes sociales permite a las personas acceder forma rápida y gratuita a los contenidos generados por los turistas que ya han experimentado determinada experiencia. Este contenido puede influir en la elección de otros turistas, lo que impone una nueva dinámica a las relaciones de consumo, influyendo en la imagen y en la competitividad de los destinos. Este estudio investigó la imagen proyectada por turistas que visitaron Río de Janeiro en los años 2015 y 2016, con relación a los siguientes aspectos: experiencia en los principales atractivos de la ciudad, calidad percibida de los servicios y juicio de precio y valor. Con este fin, se realizó un análisis de contenido de 612 comentarios publicados en el sitio TripAdvisor, el medio social dedicado al turismo de mayor audiencia en el mundo. Los resultados muestran que la mayoría de los turistas relató experiencias positivas, evaluó positivamente la calidad de los servicios y el valor, presentando altos niveles de satisfacción en los principales atractivos de la ciudad. Las dimensiones de la experiencia más presentes en los comentarios fueron la estética y el entretenimiento, reforzando la importancia de las bellezas naturales y arquitectónicas en la formación de la imagen de Río de Janeiro. En cuanto a los comentarios con contenido negativo, el análisis del reveló puntos que deben ser monitoreados y mejorados por gestores públicos y privados vinculados al turismo. Palabras clave: Turismo; Medios sociales; Contenido generado por el usuario; Imagen de destinos turísticos; Comportamiento del consumidor.

\section{INTRODUÇÃO}

Com o desenvolvimento de novas tecnologias da informação, o comportamento do consumidor passou por importantes mudanças, como o compartilhamento de percepções e avaliações nas mídias sociais, conhecido também por "conteúdo gerado pelo usuário", escrito pelos próprios consumidores, que transmitem suas opiniões a respeito das experiências vivenciadas. Por essa razão, o compartilhamento de experiências em sites como TripAdvisor se tornou importante fonte de informação para o planejamento de viagens. Pesquisas indicam que as informações disseminadas por turistas influenciam as escolhas de serviços e a imagem dos destinos turísticos (Baka, 2016; Litvin, Goldsmith \& Pan, 2011; Xiang \& Gretzel, 2010).

A imagem dos destinos é formada por um conjunto complexo de atributos internos e externos fortemente influenciados pela mídia tradicional, pelo cinema 
e por outras formas de propagação, artísticas ou midiáticas, controladas por reduzido número de grupos sociais de interesse (Baloglu \& Mccleary, 1999; Beerli \& Martín, 2004). No entanto, essa realidade se modifica no momento em que turistas têm a chance de produzir conteúdo por meio do relato de suas experiências, que é capaz de interferir na formação da imagem de marcas e de lugares.

Dada a importância dessa realidade, que impõe uma nova dinâmica às relações de consumo, afetando a competitividade dos destinos, este estudo teve como objetivo investigar a imagem projetada em mídias sociais por turistas brasileiros e estrangeiros que visitaram a cidade do Rio de Janeiro em relação aos seguintes aspectos: experiência vivenciada nos principais atrativos da cidade, qualidade percebida dos serviços prestados e julgamento de preço e valor. Para tal, foram analisados 612 comentários postados no site TripAdvisor, a mídia social dedicada ao turismo de maior audiência no mundo, nos anos 2015 e 2016.

\section{A DISSEMINAÇÃO DA EXPERIÊNCIA TURÍSTICA NA INTERNET}

O compartilhamento de experiências por consumidores e turistas é uma importante fonte de informações sobre produtos e, especialmente, serviços, uma vez que esses últimos possuem natureza intangível. As mídias sociais deram espaço para que a influência interpessoal se dê no âmbito on-line, permitindo a produção e a troca de conteúdos de maneira informal e desinteressada entre indivíduos. Segundo Liu e Park (2015), os comentários on-line se tornaram fonte importante de informação nos processos de consumo.

O Conteúdo Gerado pelo Usuário (CGU) é toda e qualquer manifestação que um internauta produza na rede, envio de arquivos (fotos, vídeos, documentos), informações e mídias geradas pelo público em geral (Arriga \& Levina, 2008). Na dinâmica do CGU, o usuário é o ponto central da atividade, pois exerce simultaneamente os papéis de produtor e consumidor de conteúdo na internet. Esse conteúdo é considerado aliado dos turistas na hora de planejar suas viagens e mudou profundamente a dinâmica da atividade turística.

o CGU tem sido usado de forma mais frequente para comunicar e compartilhar informações relacionadas a viagens, auxiliando o planejamento de viagens e gerando expectativas em outros turistas (Gretzel \& Yoo, 2008; Leung et al., 2011). No lugar de fotos editadas e manipuladas em brochuras, folhetos ou anúncios, turistas podem basear suas escolhas em relatos espontâneos e fotos mais realistas postadas por outros turistas. Além de reduzir o nível de incerteza dos futuros consumidores, esse conteúdo afeta a reputação dos destinos turísticos, já que as informações estão disponíveis gratuitamente de forma on-line (Baka, 2016). Os comentários são capazes de complementar e até mesmo competir com informações fornecidas pelos sites oficiais dos atrativos turísticos (Wong \& Qi, 2017). Por isso as empresas, especialmente aquelas voltadas para o setor de experiências, como os atrativos turísticos, precisam valorizar as avaliações dos consumidores nas mídias sociais (Fang, Ye, Kucukusta \& Law, 2016).

Entre as plataformas on-line que permitem a produção de conteúdo coletivo voltado para o turismo, a de maior destaque e importância é o TripAdvisor. Suas 
principais funções são o recolhimento e a difusão de conteúdos gerados pelo usuário, como opiniões, classificações, fotos e vídeos, no âmbito da experiência turística. 0 TripAdvisor (2016) se considera a maior comunidade de viagens do mundo, com 340 milhões de visitantes por mês e 350 milhões de avaliações e opiniões, cobrindo mais de 6,5 milhões de acomodações, restaurantes e atrações. Lee, Law e Murphy (2011) reputam os colaboradores do site como "massa crítica" relevante e ainda ressaltam entre eles os chamados "revisores úteis", que seriam aqueles que viajam mais e postam comentários ativamente, pertencendo a todas as faixas etárias e grupos de gênero. Muitos autores que estudaram a dinâmica do CGU consideram o TripAdvisor o mais relevante site de conteúdo gerado pelo turista (Buhalis \& Law, 2008; Livtin, Goldsmith \& Pan, 2011; Jeacle \& Carter, 2011).

\section{A INFLUÊNCIA DO CGU NA IMAGEM DE DESTINOS TURÍSTICOS}

A relevância do TripAdvisor no contexto do CGU motivou estudos recentes sobre a imagem de destinos e atrativos turísticos sob diferentes óticas: Baka (2016) realizou um estudo sobre o gerenciamento da reputação on-line; Pantano, Priporas e Stylus (2017) pesquisaram as preferências futuras de turistas; Wong e Qi (2017) analisaram a evolução da imagem de Macau. Esses trabalhos indicam que o TripAdvisor é um repositório muito utilizado, capaz de refletir as percepções dos turistas e influenciar a reputação e imagem dos destinos turísticos.

Chen e Tsai (2007) definem a imagem do destino como a representação dos conhecimentos de uma pessoa, seus sentimentos e percepções de um determinado destino. Os autores também apresentam a importância da imagem no comportamento do visitante em duas vertentes: a primeira está ligada à influência sobre o processo de tomada de decisão na escolha do destino; a segunda, ao condicionamento dos comportamentos pós-decisórios como participação, avaliação e intenções futuras.

Chagas (2008) explica que o conceito de imagem é formado pela interpretação do consumidor, seja fundamentada ou emocional, a partir de suas avaliações cognitivas e afetivas. A dimensão afetiva se refere aos fatores sentimentais entre o consumidor turístico e o destino (Chagas, 2008). Segundo Baloglu e McCleary (1999), tal dimensão está relacionada à avaliação da qualidade a partir de fatores pessoais. Beerli e Martín (2004) afirmam que a avaliação afetiva é formada por aspectos psicológicos (valores, motivação, personalidade) e sociais (educação, status, idade), que diferem de pessoa para pessoa.

A dimensão cognitiva é a dos aspectos intelectuais, ou seja, a análise do destino é feita de forma racional, baseada em fatores mensuráveis (Chagas, 2008). Baloglu e McCleary (1999) explicam que a avaliação cognitiva tem base no conhecimento sobre atributos objetivos do lugar. Para Beerli e Martín (2004), a avaliação cognitiva é formada pela soma de fontes de informação (mídia tradicional, filmes, redes sociais), experiência anterior e materiais de distribuição (mapas, elementos de comunicação de marketing, guias turísticos).

Com base nessas visões da literatura, é apropriado concluir que a imagem de um destino será influenciada por uma série de fatores, entre eles as avaliações 
cognitivas e afetivas postadas por turistas em mídias sociais. Essas avaliações refletem as experiências vivenciadas pelos usuários, que assumem papel de interlocutores dos diferentes locais visitados (Baka, 2016). Sendo assim, o CGU construído na plataforma do TripAdvisor é fonte de informação com potencial de influenciar a escolha do turista.

\section{EXPERIÊNCIA TURÍSTICA E QUALIDADE PERCEBIDA}

Turistas costumam viajar na expectativa de acontecimentos memoráveis que marquem de alguma forma suas vidas. Esses acontecimentos são chamados de experiências e podem representar para momentos únicos, especiais ou extraordinários (Pezzi \& Santos, 2012). Segundo Pérez (2009), a experiência turística integra sons, odores, cores, relação com outros, diversão, hospitalidade, atividades, enriquecimento, relação custo-benefício, acessibilidade, entre outros fatores que compõem os atrativos de um destino.

Como os destinos de viagens englobam produtos turísticos, as experiências vivenciadas por indivíduos em atrativos e serviços influenciam a imagem do destino. Essas experiências são individuais, portanto, a mesma experiência pode ser percebida de diferentes maneiras (Pine \& Gilmore, 1999). Caso o turista não tenha vivenciado a experiência esperada ou prometida, a imagem do destino poderá ficar comprometida.

Como forma de classificar os diferentes tipos de experiência que podem ser proporcionadas a um indivíduo, Pine e Gilmore (1999) propuseram um modelo com quatro domínios da experiência: entretenimento, educacional, escapismo e estética. Entretenimento tem a ver com absorção passiva e envolve estímulos que utilizam os sentidos do indivíduo para ocupar sua atenção de maneira agradável e divertida. De forma oposta, o indivíduo que tem uma experiência educacional absorve ativamente a experiência, eventos educacionais podem envolver a mente e o corpo, e para que a experiência ocorra, o viajante precisa aprender com a atividade e informar-se a respeito do conteúdo apresentado, de forma que os seus conhecimentos sejam ampliados. 0 domínio do escapismo também é caracterizado pela participação ativa, mas a experiência acontece de forma imersiva. A pessoa se envolve com o ambiente, pois é ela quem faz a experiência acontecer (Pine \& Gilmore, 1999). No domínio estético, para que a experiência aconteça, a pessoa precisa apenas estar em determinado local e observar os elementos do ambiente. Quando indivíduos vivenciam uma experiência estética, estão imersos na atividade, mas participam de forma passiva. Cada uma dessas dimensões pode estar presente em diferentes atrativos de um destino turístico, moldando sua imagem e definindo seu perfil competitivo. Alguns destinos serão valorizados por sua capacidade de oferecer experiências educacionais, enquanto outros serão lembrados como locais de imersão estética.

Percebe-se que o tipo de experiência turística é capaz de interferir na imagem de um destino turístico. Portanto, os produtos que compõem o destino, incluindo os atrativos, precisam proporcionar experiências não apenas positivas, mas também memoráveis (Pine \& Gilmore, 1999). As experiências memoráveis e que superam as expectativas dos turistas auxiliam na competitividade do destino e também estão associadas com a qualidade percebida dos serviços. 


\section{Qualidade Percebida em Serviços}

A satisfação do turista depende das experiências vivenciadas nos atrativos de um destino, o que inclui a qualidade dos serviços prestados, que é baseada nas percepções e avaliações que os clientes fazem a respeito do serviço, o que pode acontecer durante ou após a prestação deste serviço (Gianesi \& Corrêa, 1994). A qualidade percebida deve corresponder ou até mesmo superar as expectativas dos clientes (Ghobadian, Speller \& Jones, 1994), que são variáveis e influenciadas pela imagem que os turistas têm do destino. A qualidade de serviços vem sendo estudada desde a década de 1980, e os estudos mais influentes baseiam-se na comparação entre expectativas e experiências para diversos atributos da qualidade (Gronroos, 2003).

Parasuraman, Zeithaml \& Berry (1988) criaram o modelo Servqual, instrumento que mede como os clientes avaliam um serviço com base em cinco atributos denominados determinantes da qualidade percebida. 0 primeiro desses determinantes é a confiabilidade, que envolve a execução do serviço de forma segura, correta, dentro do prazo estipulado e que desperte a confiança do consumidor. A tangibilidade é o determinante relacionado a equipamentos, instalações físicas, pessoal e material. A empatia envolve a atenção individualizada dada ao cliente pela organização, inclui o esforço em atender as necessidades particulares dos clientes. 0 determinante da prontidão está relacionado a atendimento imediato e respostas rápidas, além da disposição em ajudar os clientes e execução adequada dos serviços. Por fim, a segurança é a ausência de risco ou dúvida durante a prestação de um serviço.

No campo do turismo, Mondo (2014) propôs um modelo específico para avaliação da qualidade percebida em atrativos. Esse modelo envolve os seguintes determinantes: acesso, ambiente, elemento humano, experiência, segurança e qualidade técnica. A categoria acesso trata da chegada dos turistas ao atrativo turístico, envolve acessibilidade para Pessoas com Deficiência (PCD), facilidade de compra, tempo de espera pelo serviço, entre outros fatores. Já o ambiente está relacionado com a temperatura e se o lugar é convidativo e confortável. 0 elemento humano se refere ao atendimento dispensado por guias e monitores, por exemplo; no entanto, nem sempre está presente nos atrativos turísticos. A categoria experiência, adaptada de Pine e Gilmore (1999), envolve aprendizado, entretenimento, estética e evasão (escapismo). A segurança é um determinante que envolve a percepção do cliente com relação à segurança do serviço prestado. A qualidade técnica representa as questões operacionais do atrativo, como preço, infraestrutura, sinalização, capacidade de carga, entre outros (Mondo, 2014).

Gronroos (2003) afirma que a imagem de um local depende da qualidade percebida pelos clientes, portanto, se a percepção for negativa, a imagem é afetada de forma negativa. Assim, pode-se afirmar que é relevante analisar como turistas avaliam diferentes dimensões da qualidade dos serviços prestados nos atrativos de um destino.

\section{Atrativos Turísticos e a Imagem dos Destinos}

Atrativo turístico pode ser conceituado como um lugar, objeto ou acontecimento que motiva o deslocamento de turistas. Os atrativos fazem parte da 
oferta turística e são grandes responsáveis pelo interesse de indivíduos em visitar um destino (Barreto, 2008; Beni, 2009). Eles representam a razão de ser do turismo, pois são capazes de movimentar o sistema e, além disso, podem auxiliar na educação, preservação do patrimônio histórico e proteção da natureza (Mondo, 2014).

Se um atrativo for planejado e gerido da maneira correta, poderá atender bem a demanda e proporcionar experiências memoráveis para quem o visitar. Ao planejar um atrativo, é preciso pensar na frequência esperada e adaptá-lo ao perfil dos turistas. Alguns atrativos podem despertar o interesse de um grande número de visitantes, por isso é necessário controlar o fluxo de pessoas, além de treinar os funcionários para atendê-las de forma adequada, manter equipamentos em bom estado e boa aparência, sinalizar o local para facilitar o acesso, oferecer segurança para os visitantes, entre outros fatores que podem influenciar de forma positiva na experiência do turista (Mondo, 2014).

Os atrativos podem representar a principal imagem que as pessoas formam de um lugar. A cidade do Rio de Janeiro, por exemplo, é composta de diversos atrativos conhecidos internacionalmente, como o Pão de Açúcar, o Corcovado e o Maracanã. As experiências vivenciadas no Rio de Janeiro e a qualidade percebida nos serviços oferecidos na cidade estão relacionadas às visitas aos atrativos turísticos. Sendo assim, atrativos representam mais que locais de lazer e desempenham papel fundamental na formação da imagem do Rio de Janeiro.

\section{MÉTODO}

Foi realizado um estudo de natureza exploratória, com a combinação de abordagens qualitativas e quantitativas. 0 método escolhido para análise dos comentários postados pelos turistas foi a análise de conteúdo, conjunto de técnicas que tem o objetivo de descrever o conteúdo existente em processos de comunicação orais, visuais ou escritos. São utilizados procedimentos sistemáticos de codificação, categorização e quantificação do conteúdo, proporcionando a análise e o levantamento de indicadores (quantitativos ou qualitativos) para interpretação dos significados e inferência de conhecimentos (Bardin, 1977).

A rede social dedicada ao turismo TripAdvisor foi escolhida por sua importância, pela quantidade de usuários e pelo volume de comentários que mobiliza. As informações postadas pelos turistas são públicas, o que facilita o processo de coleta. No entanto, não há informações gerais sobre a cidade do Rio de Janeiro, mas sobre seus atrativos turísticos. Consequentemente, foi escolhido um conjunto de atrativos relevantes no contexto do turismo da cidade, selecionados com base no ranking do TripAdvisor de "melhores atrações" da cidade do Rio de Janeiro. Dentre os mais relevantes, excluíram-se os que não oferecem prestação de serviços estruturada (como praias e parques), uma vez que um dos objetivos da pesquisa é conhecer a percepção dos turistas em relação à qualidade dos serviços na cidade. Além disso, foram incluídos atrativos construídos em virtude dos investimentos de preparação da cidade para os Jogos Olímpicos de 2016. Os atrativos pesquisados foram Corcovado, Pão de Açúcar, Sambódromo, Maracanã e Museu de Arte do Rio (MAR). O Museu do Amanhã não foi incluído neste estudo porque foi inaugurado em dezembro de 2015, e, 
portanto, não haveria como estabelecer a comparação com o período definido para o levantamento de dados.

Foram coletados comentários dos anos de 2015 e 2016 com o objetivo de estabelecer um comparativo. 0 período escolhido para a amostra foi o carnaval (de sexta até quarta-feira de cinzas), de 13 a 18 de fevereiro de 2015 e de 5 a 10 de fevereiro de 2016. Por se tratar da alta estação, há grande presença de turistas na cidade em curto período de tempo, o que facilita a coleta de dados. Esse período foi suficiente para coletar uma quantidade relevante de comentários sobre os atrativos Corcovado e Pão de Açúcar, mas a quantidade de comentários sobre os outros atrativos foi muito pequena, foi o caso do Sambódromo, do Maracanã e do MAR. Os comentários de residentes da região metropolitana do Rio de Janeiro foram excluídos, assim como comentários em português de pessoas que não informaram suas procedências. Foram eliminados também comentários que informavam que a visita ao atrativo não ocorreu no ano em que postou o comentário. Feitas as eliminações, foram selecionados 612 comentários de turistas para a amostra final.

Os comentários foram registrados e passaram por processo de análise e codificação, segundo categorias e conceitos pesquisados na literatura (Quadro 1).

Quadro 1 - Categorias da análise de conteúdo

\begin{tabular}{|c|c|c|}
\hline Experiência & $\begin{array}{l}\text { - Estética } \\
\text { - Escapismo } \\
\text { - Educação } \\
\text { - Entretenimento }\end{array}$ & (Pine \& Gilmore, 1999) \\
\hline \multirow[b]{2}{*}{$\begin{array}{l}\text { Qualidade } \\
\text { dos serviços }\end{array}$} & $\begin{array}{l}\text { - Confiabilidade } \\
\text { - Empatia } \\
\text { - Tangíveis } \\
\text { - Prontidão } \\
\text { - Segurança do serviço prestado }\end{array}$ & $\begin{array}{c}\text { (Parasuraman, } \\
\text { Zeithaml \& Berry, 1988) }\end{array}$ \\
\hline & $\begin{array}{l}\text { - Acesso - PCD (pessoa com deficiência); } \\
\text { compra pela internet; transporte; filas } \\
\text { - Capacidade de carga } \\
\text { - Percepção de segurança pública } \\
\text { (sensação de segurança no entorno } \\
\text { dos atrativos) } \\
\text { - Informações turísticas }\end{array}$ & (Mondo, 2014) \\
\hline $\begin{array}{l}\text { Percepção de } \\
\text { preço e valor }\end{array}$ & $\begin{array}{l}\text { - Avaliação dos preços } \\
\text { - Percepção de valor (custo x benefício) }\end{array}$ & (Monroe, 2007) \\
\hline
\end{tabular}

Fonte - Elaborado pelos autores, 2016

Para consolidação das informações e identificação da imagem projetada do Rio de Janeiro pelos turistas, optou-se pela criação de uma wordcloud. As palavras presentes na nuvem ganham tamanhos que variam de forma proporcional e de acordo com a relevância ou quantidade de vezes em que foram mencionadas (Viégas \& Watteberg, 2008; McGee \& Craig, 2012). Foram retirados da wordcloud artigos e preposições, assim como os nomes dos atrativos avaliados. Optou-se também por não traduzir os títulos em inglês e espanhol. 


\section{RESULTADOS}

\section{Perfil dos Turistas}

O TripAdvisor classifica seus colaboradores em seis níveis, estabelecendo pontuação por nível que indica a quantidade e os tipos de contribuições postadas pelo usuário (avaliações, fotos, vídeos, artigos, entre outros). Dessa forma, é possível dizer que os colaboradores de níveis mais altos são os mais ativos na comunidade e têm maior chance de influenciar a opinião de uma quantidade maior de turistas. Em relação ao nível de colaborador, 68,7\% dos 612 participantes da amostra deste estudo estavam entre os níveis de maior influência $(4,5$ e 6$)$.

Quanto ao gênero, foi encontrada quantidade equivalente de homens (42\%) e mulheres (40\%) na amostra (18\% não o informaram). A maioria dos usuários pesquisados não informou a idade (50\%), mas dos que informaram a porcentagem mais significativa estava na faixa de 25 a 49 anos (36\%).

Quanto à origem dos turistas, 362 se identificaram com nacionalidades estrangeiras (50\%) e 195 como brasileiros (38\%). Dentre os estrangeiros, o país com a maior representatividade foi a Argentina (20\%), seguida por Reino Unido $(6,1 \%)$, Chile (5,8\%) e Estados Unidos (3,6\%). Em relação aos turistas nacionais, São Paulo foi o estado com maior número de usuários (11\%), seguido por Rio Grande do Sul (3,2\%), Distrito Federal (2,8\%), Minas Gerais e Paraná (2,5\% cada).

\section{Experiência nos Atrativos}

Na avaliação dos comentários, foi possível identificar que 562 turistas (92\%) relataram experiências positivas, 25 (4\%) relataram experiências negativas e outros 25 (4\%) não informaram se suas experiências foram positivas ou negativas. Ao comparar a quantidade de experiências positivas e negativas relatadas nos anos de 2015 (92\%) e 2016 (91\%), percebe-se que não houve mudança significativa.

A dimensão da experiência (Pine \& Gilmore, 1999) mais presente nos comentários dos turistas (Quadro 2) foi a estética, com 127 menções em 2015 (51\%) e 183 menções em 2016 (50\%). Os turistas demonstram em seus relatos grande entusiasmo em relação à beleza natural das paisagens do Rio de Janeiro, em especial quando visitam atrativos como o Corcovado e o Pão de Açúcar. Mesmo sendo a beleza natural a maior responsável pela experiência positiva, muitos comentários também ressaltam a beleza arquitetônica do MAR e do estádio do Maracanã, além da beleza estética dos desfiles das escolas de samba. A segunda dimensão da experiência mais citada pelos turistas foi o entretenimento, com 73 menções em 2015 (30\%) e 151 em 2016 (41\%). A dimensão da educação também esteve presente nos relatos sobre a experiência nos atrativos pesquisados (4\% em 2015; 0,3\% em 2016). No ano de 2015, apenas dois turistas mencionaram a dimensão de escapismo em seus comentários (0,8\%). Esse resultado pode ser explicado pelo fato de que para este estudo foram selecionados atrativos com características mais contemplativas, onde o turista vivencia a experiência como um espectador, sem participação ativa. 
Quadro 2 - Exemplos de comentários nas diferentes dimensões da experiência

\begin{tabular}{|c|c|c|}
\hline \multicolumn{3}{|c|}{ Experiência nos Atrativos } \\
\hline $\begin{array}{l}\text { Dimensões da } \\
\text { Experiência }\end{array}$ & Comentários positivos & Comentários negativos \\
\hline Estética & $\begin{array}{l}\text { “O monumento é muito bonito e o lugar } \\
\text { possui uma vista privilegiada da cidade } \\
\text { do Rio de Janeiro" (Corcovado 2016, } \\
\text { colaborador nível 6). } \\
\text { "Um dos mais belos pontos turísticos do Rio } \\
\text { de Janeiro" (Pão de Açúcar 2015, colaborador } \\
\text { nível 4). } \\
\text { "Muito lindo o estádio modificado para a Copa } \\
\text { do Mundo de 2014" (adaptado do espanhol) } \\
\text { (Maracanã 2016, colaborador nível 5). } \\
\text { "Recomendo a todos que façam essa escolha } \\
\text { e assistam pelo menos uma vez na vida esse } \\
\text { show de alegria e cores que é muito belo!” } \\
\text { (Sambódromo 2015, colaborador nível 5). } \\
\text { "A arquitetura do prédio é um deslumbre!” } \\
\text { (MAR 2016, colaborador nível 3). }\end{array}$ & $\begin{array}{l}\text { "Fui em um dia nublado, por } \\
\text { isso não pude apreciar a vista } \\
\text { (adaptado do espanhol)" } \\
\text { (Corcovado 2015, colaborador } \\
\text { nível 6). } \\
\text { "Obviamente, a vista não é } \\
\text { bonita em um dia que não } \\
\text { esteja claro (adaptado do } \\
\text { inglês)" (Pão de Açúcar 2016, } \\
\text { colaborador nível 6). } \\
\text { "Conhecemos alguns dias antes } \\
\text { dos desfiles de carnaval e ainda } \\
\text { estavam pintando e realizando } \\
\text { os últimos retoques (adaptado } \\
\text { do espanhol)" (Sambódromo } \\
\text { 2015, colaborador nível 3). }\end{array}$ \\
\hline Entretenimento & $\begin{array}{l}\text { "É um passeio obrigatório se você está no } \\
\text { Rio, vale totalmente a pena (adaptado do } \\
\text { espanhol)" (Corcovado 2015, colaborador } \\
\text { nível 3). } \\
\text { "A melhor coisa em visitar o Pão de Açúcar é } \\
\text { se você está no Rio de Janeiro (adaptado do } \\
\text { inglês)" (Pão de Açúcar 2016, colaborador } \\
\text { nível 4). } \\
\text { "Achei que o passeio valeu a pena" (Maracanã } \\
\text { 2015, colaborador nível 4). }\end{array}$ & $\begin{array}{l}\text { "O passeio foi entediante } \\
\text { e escandalosamente curto } \\
\text { (adaptado do inglês)" (Maracanã } \\
\text { 2016, colaborador nível 5). } \\
\text { "Realmente eu não gostei [...] } \\
\text { não passa de uma rua grande } \\
\text { com grades ao seu redor } \\
\text { (adaptado do espanhol)" } \\
\text { (Sambódromo 2015, } \\
\text { colaborador nível 2). }\end{array}$ \\
\hline Educação & $\begin{array}{l}\text { "Existem muitas histórias interessantes sobre } \\
\text { a construção e o morro" (Corcovado 2015, } \\
\text { colaborador nível 5). } \\
\text { "Muito interessante esse museu com obras } \\
\text { diversas, quadros, esculturas e uma mostra } \\
\text { maravilhosa de fotografias antigas e também } \\
\text { premiadas" (MAR 2016, colaborador nível 6). } \\
\text { "O ambiente é muito bom com informações } \\
\text { bem detalhadas, exposições bem interessantes } \\
\text { [...] Aprendi muito, vi muita coisa legal e } \\
\text { recomendo para quem visitar o Rio" (MAR } \\
\text { 2015, colaborador nível 4). }\end{array}$ & \\
\hline Escapismo & $\begin{array}{l}\text { "Tive o privilégio de desfilar pelo grupo } \\
\text { especial neste último carnaval. As } \\
\text { arquibancadas te incentivando, brincando } \\
\text { junto contigo, tudo é o máximo!" } \\
\text { (Sambódromo 2015, colaborador nível 6). } \\
\text { "Sou até suspeito em avaliar, afinal desfilo } \\
\text { pela Unidos de Vila Isabel. Energia recíproca, } \\
\text { sinergia total" (Sambódromo 2015, } \\
\text { colaborador nível 5). }\end{array}$ & \\
\hline
\end{tabular}

Fonte - Elaborado pelos autores, 2016 


\section{Qualidade Percebida dos Serviços}

Menções relacionadas aos determinantes da qualidade percebida (Parasuraman et al., 1988; Mondo, 2014) foram identificadas em 415 dos comentários avaliados (68\%), sendo 315 (51\%) com teor positivo e 100 (16\% da amostra) com teor negativo. No comparativo entre os anos de 2015 e 2016, a quantidade de comentários com teor positivo saltou de $40 \%$ em 2015 para $60 \%$ em 2016. Foi possível ainda constatar que a maioria dos comentários de 2015 tem caráter informativo, e são dedicados a esclarecer os demais usuários da comunidade TripAdvisor quais eram os preços e os melhores meios de transporte para chegar ao atrativo em questão. Nos comentários de 2016, por outro lado, foi possível identificar um volume maior de comentários expondo as experiências vividas no atrativo e as condições de qualidade percebidas nos serviços.

Dos determinantes da qualidade percebida propostos por Parasuraman, Zeithaml e Berry (1988), a dimensão mais presente nos comentários dos turistas foi a confiabilidade: foram 61 menções em 2015 (25\%) e 177 menções em 2016 (48\%). Nos comentários positivos, é possível identificar que os turistas expressam sua satisfação ao receber um serviço prestado com eficiência, nos horários e no formato prometido pela empresa gestora. Nos comentários negativos, os turistas demonstram seu desapontamento quando recebem um serviço insatisfatório, que não oferece qualidade condizente com o esperado, marcado por má gestão nas filas e desorganização na espera.

A dimensão "tangíveis" foi a que recebeu mais citações dos turistas depois da confiabilidade, foram 44 comentários relacionados aos aspectos físicos dos atrativos em 2015 (18\%) e 85 em 2016 (23\%). Em relação a essa dimensão, os turistas se admiraram com a aparência e a funcionalidade das instalações nos comentários positivos, e identificaram problemas como falta de manutenção e de equipamentos necessários para o bom serviço nos negativos. A dimensão empatia recebeu 15 menções em 2015 (6\%) e onze em 2016 (3\%), enquanto prontidão não foi mencionada em nenhum dos comentários analisados. A dimensão segurança da prestação de serviços teve seis menções em 2015 (2\%) e quatro em 2016 (1\%).

Em relação aos determinantes da qualidade dos atrativos turísticos propostos por Mondo (2014), foram analisados acesso, capacidade de carga, informações turísticas e percepção de segurança pública. No determinante acesso (transporte, fila, compra de ingressos pela internet e PCD), o transporte foi o quesito que mais apareceu nos comentários da amostra: 53 menções em 2015 (21\%) e 67 menções em 2016 (18\%). Nesses comentários, é possível identificar a preocupação dos turistas em indicar para a comunidade os melhores caminhos, rotas e meios de transporte disponíveis. 0 quesito fila também mereceu número considerável de citações, principalmente no ano de 2016, com 34 comentários (9\%), quantidade superior a 2015, quando foram feitos catorze (6\%) com esse teor. Os turistas mostraram sua insatisfação com longas filas e com a falta de estratégias de gerenciamento para amenizar a espera. 0 quesito compra de ingressos pela internet valeu dez comentários em 2015 (4\%) e outros dez em 2016 (2\%). Já a estrutura para PCD (pessoa com deficiência) foi assunto de dois comentários em 2015 (1\%) e nove em 2016 (2\%). 
A capacidade de carga dos atrativos foi citada, na maioria das vezes, de forma negativa: foram 64 comentários negativos $(9,3 \%)$, contra oito positivos $(1,2 \%)$. Os turistas se mostram insatisfeitos com a forma como a capacidade de carga é gerenciada nos atrativos. Muitos se desapontam por não ter conseguido aproveitar o atrativo em sua totalidade por conta da superlotação. Um número pequeno de turistas avaliou as informações turísticas em seus comentários, da amostra total, foram dez comentários positivos (1,5\%) e 14 negativos (2,3\%). Também foram poucas as menções de turistas relacionadas à segurança pública dentro e no entorno dos atrativos, tanto no ano de 2015 quando em 2016, contabilizando 21 turistas com comentários positivos e onze com negativos. 0 comentário de uma turista que visitou o Sambódromo em 2016 exemplifica a percepção de falta de segurança: "Tudo muito confuso, muitos bloqueios e assaltantes, o que me fez sentir insegura". Outro turista, que visitou o Corcovado em 2016, teve percepção de segurança positiva: "Tinha aglomeração de gente, mas a polícia militar controlava de forma adequada" (adaptado do espanhol) (Quadro 3).

Quadro 3 - Qualidade percebida dos serviços

\begin{tabular}{|c|c|c|}
\hline \multicolumn{3}{|c|}{ Qualidade Percebida dos Serviços } \\
\hline $\begin{array}{c}\text { Qualidade Percebida } \\
\text { dos Serviços }\end{array}$ & Comentários positivos & Comentários negativos \\
\hline Confiabilidade & $\begin{array}{l}\text { “Imperdível. Bem organizado } \\
\text { apesar de estar em reforma" } \\
\text { (Corcovado 2016, colaborador } \\
\text { nível 2). } \\
\text { "Uma experiência única... que } \\
\text { vale muito a pena ser vivida.... } \\
\text { É muita emoção e alegria.... Fiquei } \\
\text { impressionado com a organização } \\
\text { e segurança" (Sambódromo 2016, } \\
\text { colaborador nível 6). } \\
\text { "Tudo está muito bem adaptado } \\
\text { para a comodidade do turista } \\
\text { (adaptado do espanhol)" (Pão de } \\
\text { Açúcar 2015, colaborador nível 5). }\end{array}$ & $\begin{array}{l}\text { “Estou no Camarote ALLEGRIA } \\
\text { 2016, está superlotado, sem } \\
\text { banheiro suficiente, comida } \\
\text { acabando rápido!!" (Sambódromo } \\
\text { 2016, colaborador nível 3). }\end{array}$ \\
\hline Tangíveis & $\begin{array}{l}\text { "A qualidade das instalações nos } \\
\text { impressionou, assim como as vistas } \\
\text { incríveis (adaptado do espanhol)" } \\
\text { (Pão de Açúcar 2016, colaborador } \\
\text { nível 4). } \\
\text { "Um estádio lindo e impactante } \\
\text { (adaptado do espanhol)" (Maracanã } \\
\text { 2015, colaborador nível 3). } \\
\text { "Uma estrutura muito boa } \\
\text { para todos" (Corcovado 2016, } \\
\text { colaborador nível 5). }\end{array}$ & $\begin{array}{l}\text { “O Rio um lugar que, quando } \\
\text { não está embaixo de chuva, está } \\
\text { embaixo de muito sol. Cobrir } \\
\text { o resto do mirante, seria uma } \\
\text { ótima ideia” (Pão de Açúcar 2016, } \\
\text { colaborador nível 3). }\end{array}$ \\
\hline
\end{tabular}




\section{Quadro 3 - Continuação}

\begin{tabular}{|c|c|c|}
\hline \multicolumn{3}{|c|}{ Qualidade Percebida dos Serviços } \\
\hline $\begin{array}{c}\text { Qualidade Percebida } \\
\text { dos Serviços }\end{array}$ & Comentários positivos & Comentários negativos \\
\hline Empatia & $\begin{array}{l}\text { "A guia é uma graça e explica } \\
\text { graciosamente todos os detalhes } \\
\text { com paciência e humor" } \\
\text { (Maracanã 2015, colaborador } \\
\text { nível 5). } \\
\text { "Os funcionários bastante } \\
\text { atenciosos" (MAR 2015, } \\
\text { colaborador nível 5). } \\
\text { "Filas pequenas, tudo organizado, } \\
\text { staff gentil" (Pão de Açúcar 2016, } \\
\text { colaborador nível 4). } \\
\text { "pessoas sorridentes nos } \\
\text { atendendo com uma atenção } \\
\text { cheia de respeito!" (Sambódromo } \\
\text { 2016, colaborador nível 6). }\end{array}$ & $\begin{array}{l}\text { "os funcionários do trem não } \\
\text { tem nenhuma solução/atitude" } \\
\text { (Corcovado 2015, colaborador } \\
\text { nível 5). } \\
\text { "Os staffs pareciam gostar de } \\
\text { nos fazer esperar (adaptado do } \\
\text { inglês)" (Pão de Açúcar 2016, } \\
\text { colaborador nível 5). } \\
\text { "A guia deu poucas informações" } \\
\text { (Maracanã 2016, colaborador } \\
\text { nível 4). }\end{array}$ \\
\hline $\begin{array}{c}\text { Segurança na } \\
\text { prestação do serviço }\end{array}$ & $\begin{array}{l}\text { "Muito grande e muito bem } \\
\text { organizado, segurança nota 10" } \\
\text { (Maracanã 2015, colaborador } \\
\text { nível 3). } \\
\text { "me senti em plena segurança } \\
\text { nesse trajeto de bondinho" (Pão } \\
\text { de Açúcar 2016, colaborador } \\
\text { nível 5). }\end{array}$ & $\begin{array}{l}\text { "As vans são muito perigosas, } \\
\text { porque elas sobem e descem } \\
\text { muito rápido, dão voltas de alto } \\
\text { risco em um caminho estreito } \\
\text { (adaptado do espanhol)" } \\
\text { (Corcovado 2015, colaborador } \\
\text { nível 6). }\end{array}$ \\
\hline Acesso - transportes & $\begin{array}{l}\text { "É muito acessível chegar de } \\
\text { metrô (adaptado do espanhol)" } \\
\text { (Maracanã 2015, colaborador } \\
\text { nível 3). } \\
\text { "Bom acesso, fui de transporte } \\
\text { público" (Pão de Açúcar 2016, } \\
\text { colaborador nível 2). } \\
\text { "Vans muito equipadas e staff } \\
\text { muito atencioso!" (Corcovado } \\
\text { 2015, colaborador nível 1). }\end{array}$ & $\begin{array}{l}\text { "O trem não tinha ar condicionado } \\
\text { e tivemos que esperar por muitas } \\
\text { horas (adaptado do espanhol)" } \\
\text { (Corcovado 2016, colaborador } \\
\text { nível 2). } \\
\text { "Não há estacionamento no local!" } \\
\text { (MAR 2015, colaborador nível 5). } \\
\text { "o Sambódromo, apesar da sua } \\
\text { ampla capacidade de público } \\
\text { e beleza arquitetônica, deixa } \\
\text { a desejar muito no acesso" } \\
\text { (Sambódromo 2015, colaborador } \\
\text { nível 5). }\end{array}$ \\
\hline Acesso - PDC & $\begin{array}{l}\text { "Há banheiro em todos os } \\
\text { andares, acessíveis a cadeirantes" } \\
\text { (MAR 2015, colaborador nível 4). } \\
\text { "gostei muito, organizado, } \\
\text { banheiros limpos, fácil acesso, } \\
\text { rampas que facilitam os } \\
\text { cadeirantes" (Maracanã 2016, } \\
\text { colaborador nível 4). }\end{array}$ & $\begin{array}{l}\text { "O sambódromo não tem } \\
\text { nenhuma adaptação para as } \\
\text { pessoas com necessidades } \\
\text { especiais ou pessoas de } \\
\text { mobilidade reduzida" } \\
\text { (Sambódromo 2015, colaborador } \\
\text { nível 5). }\end{array}$ \\
\hline
\end{tabular}

(continua...) 


\section{Quadro 3 - Continuação}

\begin{tabular}{|c|c|c|}
\hline \multicolumn{3}{|c|}{ Qualidade Percebida dos Serviços } \\
\hline $\begin{array}{c}\text { Qualidade Percebida } \\
\text { dos Serviços }\end{array}$ & Comentários positivos & Comentários negativos \\
\hline Acesso - Filas & $\begin{array}{l}\text { "Fui cedinho e não enfrentei filas" } \\
\text { (Pão de Açúcar 2015, colaborador } \\
\text { nível 3). } \\
\text { "Foi muito interessante visitar } \\
\text { o Museu de Arte do Rio (e não } \\
\text { foram 5-6 horas esperando na } \\
\text { fila)" (MAR 2016, colaborador } \\
\text { nível 5). } \\
\text { "Demos sorte no passeio e não } \\
\text { esperamos mais que } 10 \text { minutos } \\
\text { para subir no trem" (Corcovado } \\
\text { 2016, colaborador nível 4). }\end{array}$ & $\begin{array}{l}\text { “Todos tiveram a mesma ideia, } \\
\text { por isso as filas estavam longas } \\
\text { (adaptado do inglês)” (Pão de } \\
\text { Açúcar 2016, colaborador nível 6). } \\
\text { "Existe uma fila enorme para } \\
\text { entrar no trem" (Corcovado 2015, } \\
\text { colaborador nível 5). } \\
\text { "chegada no mínimo uma hora } \\
\text { de antecedência para evitar as } \\
\text { filas enormes" (Maracanã 2015, } \\
\text { colaborador nível 4). }\end{array}$ \\
\hline $\begin{array}{l}\text { Acesso - Compra pela } \\
\text { Internet }\end{array}$ & $\begin{array}{l}\text { “Tente reservar on-line, isso ajuda } \\
\text { a evitar as multidões (adaptado } \\
\text { do inglês)" (Corcovado 2016, } \\
\text { colaborador nível 5). } \\
\text { "Hoje é possível comprar os } \\
\text { tickets pela internet, o que te } \\
\text { permite organizar com maior } \\
\text { tempo a sua viagem e ter um } \\
\text { acesso mais rápido (adaptado do } \\
\text { espanhol)" (Pão de Açúcar 2015, } \\
\text { colaborador nível 4). } \\
\text { "Achei bem fácil comprar o } \\
\text { ingresso e também o acesso às } \\
\text { arquibancadas" (Sambódromo } \\
\text { 2016, colaborador nível 1). }\end{array}$ & $\begin{array}{l}\text { "Fizemos a compra para o dia } \\
\text { seguinte pela internet e não } \\
\text { pudemos entrar porque a UOL } \\
\text { ainda estava processando o } \\
\text { pagamento" (Pão de Açúcar 2015, } \\
\text { colaborador nível 4). } \\
\text { "Venda deveria ser via on-line } \\
\text { (computador). Hoje é por telefone } \\
\text { com envio de comprovante via } \\
\text { fax. Precisam se modernizar" } \\
\text { (Sambódromo 2015, colaborador } \\
\text { nível 6). }\end{array}$ \\
\hline Capacidade de carga & $\begin{array}{l}\text { "Duas lindas rochas são unidas } \\
\text { por um teleférico com grande } \\
\text { capacidade, cabem setenta } \\
\text { pessoas (adaptado do espanhol)" } \\
\text { (Pão de Açúcar 2015, colaborador } \\
\text { nível 6). } \\
\text { "Gigante como sempre, lindo } \\
\text { como nunca. Todos os lugarem } \\
\text { [sic] possuem cadeiras, a parte } \\
\text { interna tem uma infraestrutura } \\
\text { impecável com lanchonetes e } \\
\text { banheiros muito bons" (Maracanã } \\
2015 \text {, colaborador nível 6). } \\
\text { "O museu conta com quatro } \\
\text { andares de exposição [...] às } \\
\text { terças, a entrada é gratuita, não } \\
\text { tive nenhuma dificuldade para } \\
\text { pegar o ingresso, não havia filas" } \\
\text { (MAR 2015, colaborador nível 4). }\end{array}$ & $\begin{array}{l}\text { "Passeio maravilhoso e } \\
\text { obrigatório para quem vai ao } \\
\text { Rio, embora um pouco caro e } \\
\text { congestionado" (Pão de Açúcar } \\
\text { 2016, colaborador nível 6). } \\
\text { "É uma ótima experiência, mas } \\
\text { como mencionei no título do } \\
\text { comentário: é cheio demais } \\
\text { (adaptado do inglês)" (Corcovado } \\
\text { 2015, colaborador nível 5). } \\
\text { "Se você não chegar cedo para } \\
\text { pegar um lugar na grade do } \\
\text { sambódromo ou no andar de } \\
\text { cima no parapeito, esquece, você } \\
\text { não verá nada a não ser a parte } \\
\text { de cima dos carros alegóricos. Se } \\
\text { sair de onde está para ir comer, } \\
\text { tchau!" (Sambódromo 2016, } \\
\text { colaborador nível 4). }\end{array}$ \\
\hline
\end{tabular}


Quadro 3 - Continuação

\begin{tabular}{|c|c|c|}
\hline \multicolumn{3}{|c|}{ Qualidade Percebida dos Serviços } \\
\hline $\begin{array}{c}\text { Qualidade Percebida } \\
\text { dos Serviços }\end{array}$ & Comentários positivos & Comentários negativos \\
\hline $\begin{array}{l}\text { Informações } \\
\text { turísticas }\end{array}$ & $\begin{array}{l}\text { "Voltei depois de } 15 \text { anos e gostei } \\
\text { do que vi! Melhor que antes. Mais } \\
\text { limpo. Mais organizado. Mais bem } \\
\text { indicado!" (Sambódromo 2016, } \\
\text { colaborador nível 6). } \\
\text { "Bem sinalizado e bem cuidado, } \\
\text { espero que continue assim } \\
\text { (adaptado do espanhol)" } \\
\text { (Maracanã 2015, colaborador } \\
\text { nível 3). }\end{array}$ & $\begin{array}{l}\text { "Para quem vai assistir aos } \\
\text { desfiles de metrô, tem que andar } \\
\text { muito e por ruas sujas, sem } \\
\text { sinalização e muito escuras, } \\
\text { o que é inaceitável para um } \\
\text { evento do tamanho que é" } \\
\text { (Sambódromo 2015, colaborador } \\
\text { nível 5). } \\
\text { "Me surpreendeu o fato do } \\
\text { site oferecer informações em } \\
\text { inglês, mas dentro do museu só } \\
\text { há informações em português } \\
\text { (adaptado do inglês)" (MAR } \\
\text { 2016, colaborador nível 5). } \\
\text { "Gostei de conhecer o estádio, } \\
\text { mas eu teria gostado mais } \\
\text { se a visita guiada fosse } \\
\text { mais completa, tivesse mais } \\
\text { informações, achei pobre } \\
\text { (adaptado do espanhol)" } \\
\text { (Maracanã 2016, colaborador } \\
\text { nível 4). }\end{array}$ \\
\hline
\end{tabular}

Fonte - Elaborado pelos autores, 2016

\section{Percepção de Preço e Valor}

Comentários relacionados à avaliação de preços (Quadro 4) foram postados por 25 turistas em 2015 e 69 turistas em 2016, durante o período analisado. Do total da amostra, 63 turistas $(10,3 \%)$ consideraram os preços altos, $22(3,6 \%)$ consideraram os preços médios e nove $(1,5 \%)$ consideraram os preços baixos. A maioria dos turistas que considerou os preços como altos era procedente de países latino-americanos, cujas moedas, na época, estavam desvalorizadas em relação ao Real. Um exemplo de comentário com percepção de preço é o de uma turista que visitou o Pão de Açúcar em 2016: “Só achei salgado o preço por pessoa e também lá em cima tinha uma pequena lanchonete com preços muito altos". Apesar da declaração, a turista avaliou o atrativo com nota 5, portanto, entende-se que a percepção de valor do atrativo foi positiva. Já uma turista que visitou o MAR em 2015 inicia seu comentário informando sobre o preço baixo: "Baratíssimo de entrar (se for na terça entra de graça). 0 ambiente é muito bom, com informações bem detalhadas, exposições bem interessantes, ar condicionado no ponto ideal". Vê-se que preço baixo é um fator positivo, assim como qualidade percebida e percepção de valor. A percepção de valor dos atrativos 
pesquisados, definida como o equilíbrio entre os custos e os benefícios de uma compra (Monroe, 2007), esteve presente em 221 comentários (36\%), sendo positiva para 199 turistas (33\%). Comparando-se 2015 e 2016, aumentaram as menções positivas relacionadas à percepção de valor no segundo ano $(27 \% \mathrm{em}$ $2015 ; 36 \%$ no ano seguinte).

Quadro 4 - Percepção de preço e valor.

\begin{tabular}{|c|c|c|}
\hline & Valor positivo & Valor negativo \\
\hline $\begin{array}{c}\text { Percepção } \\
\text { de Valor }\end{array}$ & $\begin{array}{l}\text { “Adoramos, só achamos um pouco } \\
\text { caro a entrada. Mas vale a pena" } \\
\text { (Maracanã 2016, colaborador } \\
\text { nível 3). } \\
\text { "Apesar do calor infernal, da espera } \\
\text { de quatro horas na fila e dos preços } \\
\text { exorbitantes lá em cima, eu voltaria } \\
\text { mil vezes!” (Pão de Açúcar 2015, } \\
\text { colaborador nível 6). } \\
\text { "É um passeio obrigatório para quem } \\
\text { está no Rio, vale totalmente a pena } \\
\text { (adaptado do espanhol)" (Corcovado } \\
\text { 2015, colaborador nível 3). } \\
\text { “Com certeza vale a pena ver } \\
\text { pelo menos uma vez na vida!” } \\
\text { (Sambódromo 2015, colaborador } \\
\text { nível 2). }\end{array}$ & $\begin{array}{l}\text { “A vista é muito linda, mas é muito } \\
\text { caro, não vale a pena (adaptado do } \\
\text { espanhol)" (Pão de Açúcar 2016, } \\
\text { colaborador nível 4). } \\
\text { "R\$40 sem guia, não podendo } \\
\text { pisar na grama parece um roubo } \\
\text { (adaptado do espanhol)” (Maracanã } \\
\text { 2016, colaborador nível 2). } \\
\text { “Gastamos mais de } 100 \text { libras (cada } \\
\text { um) pelo ticket para o pior setor, não } \\
\text { conseguimos ver nada (adaptado } \\
\text { do inglês)" (Sambódromo 2015, } \\
\text { colaborador nível 2). }\end{array}$ \\
\hline
\end{tabular}

Fonte - Elaborado pelos autores, 2016

\section{Satisfação dos Turistas}

Uma ferramenta muito importante para a comunidade TripAdvisor é a medição da satisfação do usuário. Os turistas indicam seu nível de satisfação com os atrativos por meio de um sistema de estrelas de 1 a 5 , similar a uma escala do tipo Likert (Costa \& Silva Júnior, 2014), na qual 5 = excelente, $4=$ muito bom, 3 = razoável, 2 = ruim e 1 = horrível. Coletar essa informação possibilita calcular a média da satisfação dos turistas por atrativo e a média geral de satisfação por ano pesquisado. No comparativo entre as médias gerais de satisfação, não há diferença significativa entre os anos de 2015 (4,5 de média) e de 2016 (4,4 de média), como mostra a Figura 1.

Comparando-se as médias de satisfação por atrativo (Figura 2), percebe-se que o Pão de Açúcar recebeu a melhor classificação, com 4,7 de média. O MAR apresentou 4,4 de média, enquanto o Corcovado teve 4,5. Os atrativos Maracanã e Sambódromo dividem a avaliação mais baixa, com 4,2 de média, mas se mantêm em bom nível geral de avaliação. As notas mais baixas dadas ao Sambódromo e ao Maracanã devem-se, principalmente aos seguintes fatores: expectativas elevadas em comparação à experiência e à qualidade percebida, decepção com relação ao preço, desorganização, falta de sinalização e insatisfação com a infraestrutura dos locais. 
Figura 1 - Satisfação geral dos turistas

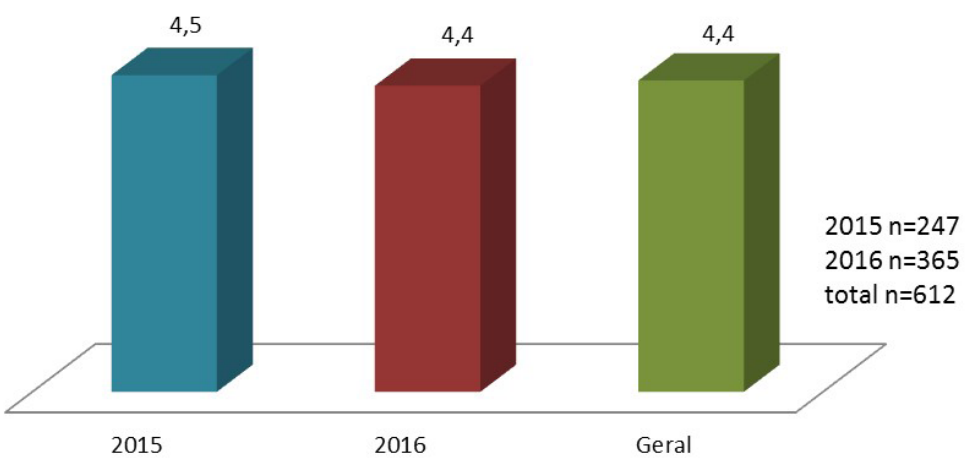

Fonte - Elaborado pelos autores, 2016

Figura 2 - Satisfação dos turistas (Média por atrativo)

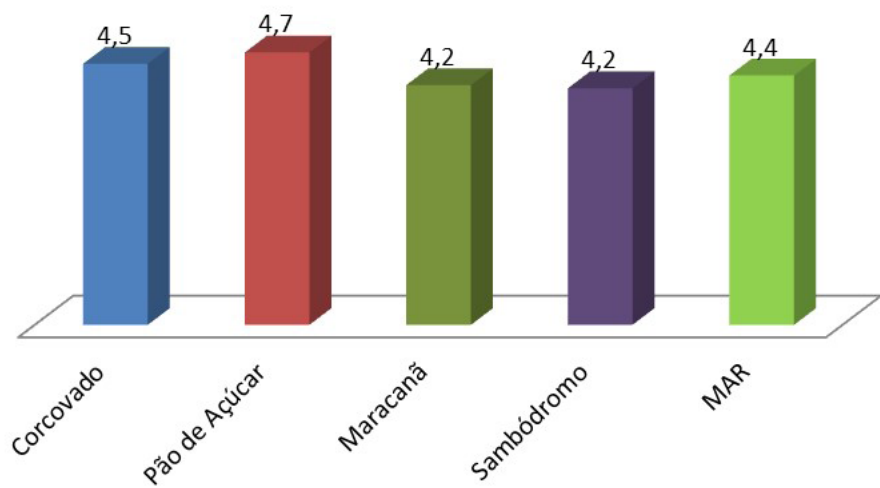

Fonte - Elaborado pelos autores, 2016

Uma turista que visitou o Maracanã em 2015 o classificou com nota 2 e fez o seguinte comentário: "Se você já visitou algum estádio não perca tempo e dinheiro indo nesse estádio, passe na frente e tire foto, só". Percebe-se que apesar de o Maracanã oferecer uma visita guiada, esta não parece ter sido suficiente para despertar o interesse e gerar alto nível de satisfação. Sobre o Sambódromo, destaca-se o seguinte comentário feito por um turista que o visitou em 2016 e avaliou o atrativo com nota 1: "Uma vergonha! Para o maior espetáculo da Terra o turista tem que sofrer para chegar, sem indicações em outros idiomas, falta de benfeitorias aos arredores, descaso com a comunidade, banheiros velhos e imundos, comida escassa, tudo sujo..." 0 turista relatou diversos aspectos negativos do Sambódromo que influenciaram de forma negativa seu nível de satisfação.

Já o Pão de Açúcar, atrativo com a média mais elevada, foi elogiado em diversos comentários. $\mathrm{O}$ alto nível de satisfação não foi resultado apenas da beleza do local, mas também da organização, pouco tempo de espera, limpeza, boa relação entre custo e benefício, entre outros fatores. Este comentário feito por uma turista que avaliou o atrativo com nota 5 no ano de 2016 é capaz de exemplificar a razão da média alta: "Tudo de bom... Bem organizado, limpo, banheiros nota 
dez... Lugar lindo, com várias opções pra lanches ou almoço... Grandioso e uma experiência maravilhosa... Perfeito... Voltaria com certeza".

\section{Imagem Projetada pelos Turistas}

Finalmente, para representar a imagem projetada pelos turistas que visitaram o Rio de Janeiro nos períodos analisados, nos anos de 2015 e 2016, foi gerada uma wordcloud com os títulos dos comentários publicados, que geralmente sumarizam o conteúdo principal do comentário, revelam aspectos cognitivos e afetivos da experiência turística e gozam de grande visibilidade entre os usuários da comunidade.

Ao se analisar a wordcloud da imagem projetada pelos turistas (Figura 3), as palavras que ganham mais destaque são as de significado positivo e estético, como "Vista", "Lindo", "Views" e "Hermoso", que são as mais citadas. Isso indica e reforça a grande apreciação dos turistas em relação às belezas naturais e arquitetônicas dos atrativos do Rio de Janeiro.

Um exemplo de título de comentário com essa característica é "Linda vista do Pão de Açúcar", feito por um colaborador nível 5 que deu nota 5 ao atrativo. Alguns títulos apresentavam apenas uma palavra, sem complemento algum, demonstrando de forma clara e simples a opinião do turista a respeito do atrativo, como "Excelente", "Imperdible", "Maravilhoso" e "Great". Como o compartilhamento de informações e sentimentos é usado como construção da imagem de um destino (Bosque, Martín, Collado \& Salmones, 2009), pode-se concluir que os títulos dos comentários do TripAdvisor a respeito dos principais atrativos turísticos da cidade do Rio de Janeiro compõem a imagem da cidade - e que esta imagem é majoritariamente positiva.

Figura 3 - Wordcloud

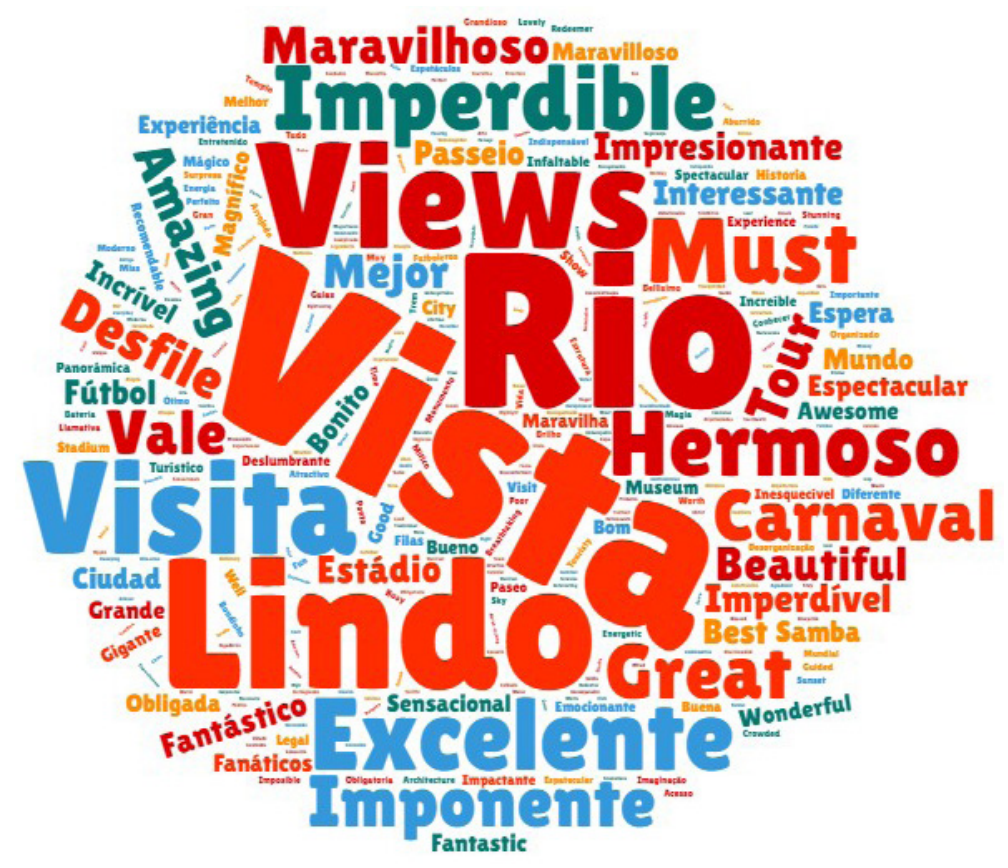

Fonte - Elaborado pelos autores, 2016 


\section{CONSIDERAÇÕES FINAIS}

O objetivo deste estudo foi investigar o teor de opiniões disseminadas por turistas brasileiros e estrangeiros, buscando conhecer a imagem projetada da cidade do Rio de Janeiro na maior mídia social de turismo da atualidade.

Os resultados indicaram alto grau de satisfação dos turistas que visitaram os principais atrativos da cidade no período do carnaval em 2015 e 2016. A análise dos relatos espontâneos postados no TripAdvisor revelou que a experiência foi muito positiva para $92 \%$ dos turistas. A dimensão estética é predominante nos discursos, seguida pela dimensão "entretenimento", ambas de participação passiva e contemplativa. Foram poucos os turistas que relataram experiências educacionais, mesmo quando o atrativo visitado era um museu. 0 escapismo, a dimensão da experiência relacionada à sensação de sair de si, de ser outra pessoa, marcou os comentários de apenas dois turistas que participaram do desfile de escolas de samba no Sambódromo. Esses resultados revelam a importância das belezas naturais e arquitetônicas na formação da imagem do Rio de Janeiro, mas também indicam que poderiam ser oferecidas aos turistas mais e melhores oportunidades para participação ativa e envolvimento em experiências de imersão e de absorção de conhecimentos. Sem isso, a experiência mantém-se na superficialidade estética, sem que os turistas se aprofundem na cultura e na história da cidade.

Os comentários dos turistas também revelaram o bom desempenho geral dos serviços prestados nos atrativos pesquisados. As dimensões confiabilidade do serviço e "tangíveis" estiveram presentes na maioria das menções espontâneas e das avaliações positivas, revelando que os turistas valorizam boa aparência física de instalações, equipamentos e funcionários; serviços prestados com regularidade, qualidade técnica e capazes de inspirar confiança - em resumo, serviços bem executados e sem surpresas. Empatia de funcionários, bom atendimento, transporte de boa qualidade, vendas pela internet, acesso facilitado para deficientes físicos e segurança também foram apreciados e enfatizados por muitos turistas.

Apesar da análise de conteúdo ter revelado na amostra apenas 16\% de comentários negativos relacionados à qualidade dos serviços, os aspectos mencionados pelos turistas devem ser cuidadosamente considerados por gestores públicos e privados. As principais queixas estiveram relacionadas à dimensão acesso, com reclamações sobre má gestão de filas e excesso de lotação (capacidade de carga). Muitas dessas reclamações dirigiam-se ao Corcovado, que após o período do Carnaval de 2016, em preparação para os Jogos Olímpicos, alterou seu sistema de gestão de filas e de venda de ingressos, o que pode ter trazido as melhorias exigidas pelos turistas da amostra. Outro aspecto negativo mencionado foi a falta de informações turísticas mais detalhadas e em outros idiomas. 0 atrativo com a maior proporção de críticas foi o Sambódromo: as reclamações foram sobre limpeza das instalações, segurança no entorno, acesso e localização de assentos, aspectos que podem alterar a experiência dos turistas durante o desfile.

Em relação aos preços, as menções espontâneas encontradas na análise de conteúdo (17\%) relataram em sua maioria preços altos. As maiores reclamações foram sobre o desfile das escolas de samba no Sambódromo. Em outros atrativos, turistas oriundos de países com câmbio desfavorável reclamaram dos preços dos ingressos.

Apesar de relatos de filas longas e preços altos, uma quantidade expressiva de turistas indicou ter valido a pena o preço que pagaram ou a espera nas filas. 
Assim, o valor percebido (equilíbrio entre sacrifícios e benefícios) foi positivo na maioria das menções. 0 que revelou deixar os turistas insatisfeitos foi exatamente o desequilíbrio do valor: esperar muito para ver um museu com acervo fraco; ou pagar um ingresso caro e não conseguir ver as escolas de samba de forma adequada.

Por fim, corroborando a análise de conteúdo, que indicou experiências positivas, boa avaliação da qualidade dos serviços e bom equilíbrio no valor percebido, a média geral de satisfação dos turistas também foi muito boa: 4,4 (5 é o máximo). A satisfação dos turistas com a experiência também é reforçada pela wordcloud, que projeta uma imagem de beleza e alegria com a visita ao Rio de Janeiro.

Este estudo mostrou a riqueza de informações presente nas postagens dos turistas feitas em mídias sociais. A análise dos comentários espontâneos revela aspectos percebidos e valorizados pelos turistas nas experiências vividas em um destino turístico, contribuindo para o monitoramento da imagem. Dentre as limitações da pesquisa, pode-se citar a amostra restrita ao período do Carnaval e a um conjunto pequeno, embora relevante, de atrativos. Pesquisas futuras podem ampliar este estudo com a inclusão de mais atrativos turísticos do Rio de Janeiro e uma amostragem que represente todo o ano. Além disso, outros métodos de análise interpretativos podem investigar o imaginário público sobre a cidade do Rio de Janeiro e como vem mudando ao longo do tempo nas mídias sociais. Recomenda-se ainda a utilização deste método para análises da imagem de outros destinos turísticos.

\section{REFERÊNCIAS}

ARRIGA, M., \& Levina, N. (2008). Social dynamics in online cultural fields. In 29 International Conference on Information Systems. Recuperado de https://goo.gl/CJrvAg

BAKA, V. (2016). The becoming of user-generated reviews: looking at the past to understand the future of managing reputation in the travel sector. Tourism Management, 53, pp. 148162, doi: 10.1016/j.tourman.2015.09.004.

BALOGLU, S., \& McCleary, K. W. (1999) A model of destination image formation. Annals of Tourism Research, 26(4), pp. 868-897, doi: 10.1016/S0160-7383(99)00030-4.

BARDIN, L. (1977). Análise de conteúdo. Lisboa: 70.

BARRETO, M. (2008). Manual de iniciação ao estudo do turismo (11ํㅡㄹ ed). São Paulo: Papirus. BEERLI, A., \& Martín, J. D. (2004). Factors influencing destination image. Annals of Tourism Research, 31(3), pp. 657-658. doi: 10.1016/j.annals.2004.01.010.

BENI, M. C. (2009). Análise estrutural do turismo (10ª ed.) São Paulo: Senac.

BOSQUE, I. R., Martín, H. S., Collado, J., \& Salmones, M. M. G. (2009). A framework for tourist expectations. International Journal of Culture, Tourism and Hospitality Research, 3(2), pp. 139-147. doi: 10.1108/17506180910962140

BUHALIS, D., \& Law, R. (2008). Progress in information technology and tourism management: 20 years on and 10 years after the Internet: the state of e tourism research. Tourism Management, 29(4), pp. 609-623. doi: 10.1016/j.tourman.2008.01.005.

CHAGAS, M. M. (2008). Imagem de destinos turísticos: uma discussão teórica da literatura especializada. Turismo Visão e Ação, 10(3), pp. 435-455. Balneário Camboriú: Univali. 
CHEN, C.-F., \& Tsai, D. (2007). How destination image and evaluative factors affect behavioral intentions? Tourism Management, 28(4), pp. 1115-1122. doi: /10.1016/j. tourman.2006.07.007.

COSTA, F. J., \& Silva Júnior, S. D. (2014). Mensuração e escalas de verificação: uma análise comparativa das escalas de Likert e Phrase Completion. Pmkt, 15. São Paulo, SP: Abep.

FANG, B., Ye, Q., Kucukusta, D., \& Law, R. (2016). Analysis of the perceived value of online tourism reviews: Influence of readability and reviewer characteristics. Tourism Management, 52, pp. 498-506, doi: 10.1016/j.tourman.2015.07.018.

GIANESI, I. G. N., \& Corrêa, H. L. (1994). Administração estratégica de serviços: operações para a satisfação do cliente. São Paulo: Atlas.

GHOBADIAN, A., Speller, S., \& Jones, M. (1994). Service quality: concepts and models. International Journal of Quality \& Reliability Management, 11(9), pp. 43-66, doi: 10.1108/02656719410074297.

GRETZEL, U., \& Yoo, K. H. (2008). Use and impact of online travel reviews. In O'Connor, W., Hopken W. \& U. Gretzel. (Orgs.). Information and communication technologies in tourism (pp. 35-46). Vienna, AT: Springer.

GRONROOS, C. (2003). Marketing gerenciamento e serviços (4⿳亠丷厂 ed.), Rio de Janeiro: Campus.

JEACLE, I., \& Carter, C. (2011). In TripAdvisor we trust: rankings, calculative regimes and abstract systems. Accounting, Organizations and Society, 36(4-5), pp. 293-309. doi: 10.1016/j.aos.2011.04.002.

LEE, H. A., Law, R., \& Murphy, J. (2011). Helpful reviewers in TripAdvisor, an online travel community. Journal of Travel \& Tourism Marketing, 28(7), pp. 675-688, doi: 10.1080/10548408.2011.611739.

LEUNG, D., Law, R., \& Lee, H. A. (2011). The perceived destination image of Hong Kong on Ctrip.com. International Journal of Tourism Research, 13(2), pp. 124-140, doi: 10.1002/ jtr.803.

LITVIN, S. W., Goldsmith, R. E., \& Pan, B. (2011). Electronic word-of-mouth in hospitality and tourism. Tourism Management, 29(3)., pp. 458-468, doi: /10.1016/j.tourman.2007.05.011.

LIU, Z., \& Park, S. (2015). What makes a useful online review? Implication for travel product websites. Tourism Management, 47, pp. 140-151, doi: 10.1016/j.tourman.2014.09.020.

MCGEE, R. G., \& Craig, J. C. (2012). What is being published? A word cloud of titles from the Journal of Paediatrics and Child Health. Journal of Paediatrics and Child Health, 48(5), pp. 452-454, doi: 10.1111/j.1440-1754.2012.02455.x.

MONDO, T. S. (2014). Tourqual: proposta de um modelo de avaliação da qualidade de serviços em atrativos turísticos. Tese de Doutorado, Centro Socioeconômico, Universidade Federal de Santa Catarina, Florianópolis.

MONROE, K. B. (2007). Pricing: making profitable decisions (3a ed.). New York: McGraw-Hill.

PANTANO, E., Priporas, C.-V., \& Stylus, N. (2017). 'You will like it!' using open data to predict tourists' response to a tourist attraction. Tourism Management, 60, pp. 430-438, doi: 10.1016/j.tourman.2016.12.020.

PARASURAMAN, A., Zeithaml, V. A., \& Berry, L. L. (1988). Servqual: A multiple-item scale for measuring consumer perceptions of service quality. Journal of Retailing, 64(1), pp. 12-40. Recuperado de https://goo.gl/W39NVe

PERÉZ, X. P. (2009). Turismo Cultural: uma visão antropológica. Tenerife, ES: Aca y Pasos, RTPC.

PEZZI, \& Santos. (2012). A experiência turística e o turismo de experiência: aproximações entre a antropologia e o marketing. In 7 Seminário de Pesquisa em Turismo do Mercosul 
(pp. 25-33). Caxias do Sul, RS: Universidade de Caxias do Sul. Recuperado de https://goo. $\mathrm{gl} / \mathrm{dEMKdt}$

PINE, B. J., \& Gilmore, J. H. (1999). The experience economy: work is theatre \& every business a stage. Massachusetts: HBS.

TRIPADVISOR. (2016, jun. 3). Recuperado de https://goo.gl/fRgQMi

VIÉGAS, F. B., \& Wattenberg, M. (2008). Tag clouds and the case for vernacular visualization. Interactions, pp. 49-52, doi: 10.1145/1374489.1374501. Recuperado de https://goo. $\mathrm{gl} / 2 \mathrm{fc} 1 \mathrm{hw}$

WONG, C. U. I., \& Qi, S. (2017). Tracking the evolution of a destination's image by text-mining online reviews - the case of Macau. Tourism Management Perspectives, 23, pp. 19-30.

XIANG, Z., \& Gretzel, U. (2010) Role of social media in online travel information search. Tourism Management, 31(2), pp. 179-188, doi: 10.1016/j.tourman.2009.02.016.

Recebido em: 20/09/2016 Aprovado em: 01/08/2017 